\title{
Part-time student selection problem with a novel hybrid approach based on DEMATEL- modified ANP and MULTIMOORA methods
}

\author{
Derya Deliktaş* and Büşra Günhan** \\ * Department of Industrial Engineering, Kütahya Dumlupınar University, Kütahya, 43100, Turkey. \\ * Computational Optimisation and Learning (COL) Lab, School of Computer Science, University of Nottingham, Nottingham, UK. \\ ** Department of Metallurgical and Materials Engineering, Kütahya Dumlupınar University, Kütahya, 43100, Turkey. \\ *Corresponding Author: derya.deliktas@dpu.edu.tr
}

Submitted : 10/01/2020

Revised :22/07/2021

Accepted :09/08/2021

\begin{abstract}
This study proposes a hybrid approach for selecting students to employ part-time within the various departments of a university. There are both qualitative and quantitative criteria for selecting students. To ensure a subjective assessment in the decision-making process, this study suggests developing a DEMATEL-modified ANP and MULTIMOORA. An empirical case study at the Metallurgical and Materials Engineering Department in Turkey was put forward to test the effectiveness of the proposed decision-making method, which provided an unbiased selection using three main and seven subcriteria. These criteria were determined per the commission members' previous experience and the principles listed in the Administration Guideline of the university. One of five candidates was selected using the novel hybrid approach. From the obtained results, all scenarios with the sensitivity analysis based on the changing decision makers' weights and the changing dimension weights indicate that the S3 student remains the most preferred alternative, and the S4 student the most suitable alternative, respectively.
\end{abstract}

Keywords: Analytic network process (ANP); Decision making trial and evaluation laboratory (DEMATEL); Multi-criteria decision-making (MCDM); MULTIMOORA; Student selection.

\section{INTRODUCTION}

During the undergraduate students' education period, they often need to pay for expenditures such as stationery, research, accommodation, transport, and daily living expenses. Most students can afford this with financial support from their families. In Turkey, if a student from a low-income family is successful enough, the government may support that student through monthly grants during the education period. Some private associations and foundations may also support low-income students. Despite these opportunities, if the student does not qualify for a government grant or funding from private associations and foundations, or if the grant is not 
enough to cover their expenses, the student will need another source of income. In these instances, the student will need to work part-time during their free periods outside their class schedules. A potential source of part-time work can be the university departments in Turkey.

A key consideration is determining the criteria weights in which to best objectively evaluate the most appropriate applicable student to employ in a university department. Pamučar et al. (2018) claimed there are no divisible methods for determining criteria weights. For this reason, a hybrid MCDM model was proposed to the participating experts. During the first stage, the integrated DEMATEL-ANP (DANP) model is used to determine the evaluation criteria weights: (i) the ANP method is used to compute the weights of evaluation clusters; (ii) the DEMATEL method is used to handle situations when inner-dependences occur within an evaluation cluster. During the second stage, the MULTIMOORA method is used to rank the candidates, which consisted of five students. A flowchart of the proposed hybrid approach is shown in Figure 1.

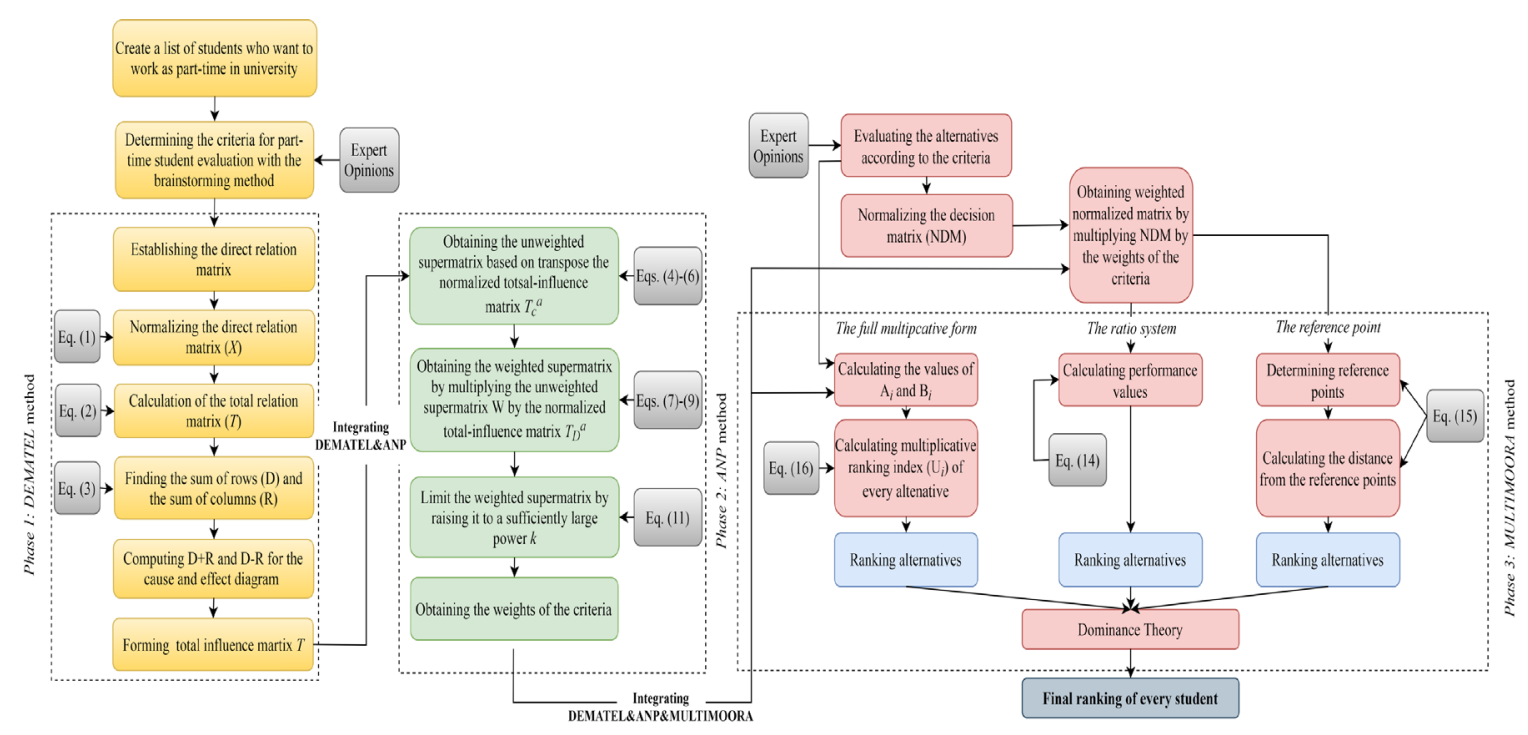

Figure 1. The flowchart diagram of the part-time student evaluation.

In many previously conducted studies, DEMATEL, ANP, and MULTIMOORA methods were widely used as powerful tools for solving MCDM problems. DANP identifies the interactions between evaluation criteria of alternatives while considering the dependencies between criteria, rather than conventional AHP, which assumes independence between criteria and subcriteria. The MULTIMOORA is used for higher quality outputs by comparing the three different approaches more reliably. Thus, the paper's main contributions can be arranged as the development of an objective evaluation process model and integrating DEMATEL-modified ANP and MULTIMOORA methods for an effective solution to the student selection problem. This study also has the application of a real case study in Turkey.

\section{LITERATURE REVIEW}

Over the years, MCDM methods have been proposed to address the student selection problems (Baki et al., 2017; De Farias Aires et al., 2017; Deliktas \& Ustun, 2017; Fadlina et al., 2017; Siahaan \& Mesran, 2017; Hasan et al., 2019; Vierula et al., 2020). Although these methods have become popularized for strategic decision-making 
since the 1990s, hybrid approaches are preferred instead of traditional MCDM methods. In the literature, there are many studies with different integrated MCDM methods such as the DEMATEL and ANP approach on the air traffic protection aircraft problem (Petrović \& Kankaraš, 2018), DEMATEL-ANP and PROMETHEE II methods on the workload stress problem for air traffic controller's (Bongo et al., 2018), DEMATEL and ANP approach on the project selection problem (Poudeh et al., 2019), DEMATEL-ANP and MOORA approach on the evaluation of financial service performance (Dinçer et al., 2019), ANP-SERVQUAL and DEMATEL approach on the performance assessment measures (Kargari, 2018), and the AHP-RAFSI approach on the location selection problem (Alossta et al., 2021). Additionally, Büyüközkan \& Güleryüz (2016) reviewed the integrated DEMATEL and ANP approaches used between the years 2007 and 2014 for various research scopes, while Koca \& Y1ldırım (2021) presented a bibliometric analysis of the DEMATEL method between the years 1999 and 2020.

In the literature, apart from the methods and conventional pairwise comparisons, such as DEMATEL and ANP mentioned above, there are have been newly emerging subjective methods with various advantages, including FUCOM (Full Consistency Method) (Pamučar et al., 2018), LBWA (Level Based Weight Assessment) model (Žižović \& Pamučar, 2019), and BWM (Best Worst Method) (Rezai, 2015; Pamučar, 2020) to determine weight coefficients of the criteria. Among these subjective approaches, the BWM method has some negative effects on the final weights of criteria. The main limitations of this method are the creation of nonglobal optimal solutions and the complexity of its calculation process (Mostafaeipour et al., 2021). However, FUCOM has higher consistency, reduced pairwise comparisons, and a more flexible measurement scale, while the LBWA method requires a smaller number of pairwise criteria comparisons and has a rational and logical-mathematical algorithm (Žižović \& Pamucar, 2019). Even though DEMATEL has some adverse effects on the final results due to its lack of consistency measure, this method is widely used to determine the interaction between criteria and the diagram of relations, and is typically used in conjunction with ANP to determine the criteria weights (Pamučar et al., 2018). Although the DANP method is not a new approach, it remains a popular method in the literature. Based on the reviewed literature, this study is the first at attempting to use an integrated DANP and MULTIMOORA as an MCDM framework to solve the selection of a student for part-time employment problem.

\section{EVALUATION METHODOLOGY}

The method of integrating the DANP and MULTIMOORA methods is summarized in this Section. The DEMATEL approach was first improved upon by the Science and Human Affairs Program of the Battelle Memorial Institute of Geneva in 1970 (Gabus \& Fontela, 1973). This method is an effective MCDM technique in finding and analyzing the direct and indirect causal relationships among different system factors. Additionally, the DEMATEL approach uses a graph theory, making it easy to understand the analysis of complex problems due to its visual method. DEMATEL can be categorized as follows:

Step 1: Defining main criteria and subcriteria for evaluating part-time student. The evaluation criteria are determined being considered the experiences and knowledge of experts with brainstorm method.

Step 2: Calculating the initial average matrix. After every expert evaluates the interactive influence degree among each pair of identified criteria, the direct-influence matrices for main criteria and subcriteria are conducted. Five scales are used to represent the degree of influence between factors, in which $0=$ "no influence", $1=$ "low influence", 2 = "medium influence", 3 = "high influence", and 4 = "very high influence".

Step 3: Calculating the normalized initial direct-influence matrix. The normalized initial direct influence matrix $\mathrm{X}$ can be acquired by multiplying A by s using Eq. (1): 
$X=S . A \Rightarrow S=\min \left[\frac{1}{\max _{i} \sum_{j=1}^{n}\left|a_{i j}\right|}, \frac{1}{\max _{j} \sum_{i=1}^{n}\left|a_{i j}\right|}\right]$

Step 4: Deriving the total-influence matrix. The total-influence matrix $T$ can be acquired using Eq.(2), in which the $I$ is denoted as the identity matrix

$T=X(I-X)^{-1}$

where $\left[t_{i j}\right]_{n x n,}$ for $i, j=1,2, \ldots, n$.

Step 5: Producing a causal diagram. The vectors $r$ and $\mathrm{c}$ are computed with the sum of rows and columns of matrix $T$ using Eq. (3), respectively. $\boldsymbol{r}+\boldsymbol{c}$ value shows the degree of importance, in which a high value means a high importance. On the other hand, criteria having positive values of $\boldsymbol{r}-\boldsymbol{c}$ are on the cause group and dispatches effects to the other criteria. If the value of $\boldsymbol{r}-\boldsymbol{c}$ is positive, the criterion falls under the causal cluster; otherwise, it is under the effect cluster

$\mathrm{r}=\left[\sum_{j=1}^{n} t_{i j}\right]_{n \times 1} \& c=\left[\sum_{i=1}^{n} t_{i j}\right]_{1 x n}^{\prime}, \mathrm{i}=1,2, \ldots, n ; j=1,2, \ldots, n$

Step 6: Obtaining a threshold value and the impact-relations map (IRM). Decision makers (DMs) must get a threshold value for the influence level in order to obtain an appropriate IRM.

Analytic Network Process (ANP) method being extended AHP (Saaty, 1996) is categorized as having three main problems: (1) it assumes the relationship structure of the evaluation system before using ANP, (2) it is hard to obtain consistent results because it is not easy to understand the ANP questionnaire because of its complexity (Chen, 2016), and the process of pairwise comparison is time-consuming, (3) and supposing that each cluster will have same equal weight seems irrational due to the different degrees of influence among the dimensions or clusters (Shao et al., 2018). These lacks can be filled with DEMATEL-modified ANP (DANP). In ANP, it is called the total-influence matrix $T_{C}=\left[t_{i j}\right]_{n \times n}$ obtained by criteria and $T_{D}=\left[t_{i j}{ }^{D}\right]_{m \times m}$ obtained by dimensions from $T_{C}$ is normalized to reach the ANP weights of dimensions with the help of the influence matrix $T_{D}$.

Step 7: Obtaining the unweighted supermatrix. The total-influence matrix $T$ obtained from

DEMATEL approach is divided into $T_{D}$ and $T_{C} . T_{D}$ is created by averaging the degrees of influence belonging to each criterion in the total-influence matrix $T$. $T_{C}$ needs to be normalized by diving its elements in row $i$ within each cluster (dimension). After the normalization of the total-influence matrix $T_{C}$ by dimensions, a new matrix $T_{C}^{\alpha}$ is formed as given in Eq. (4) 


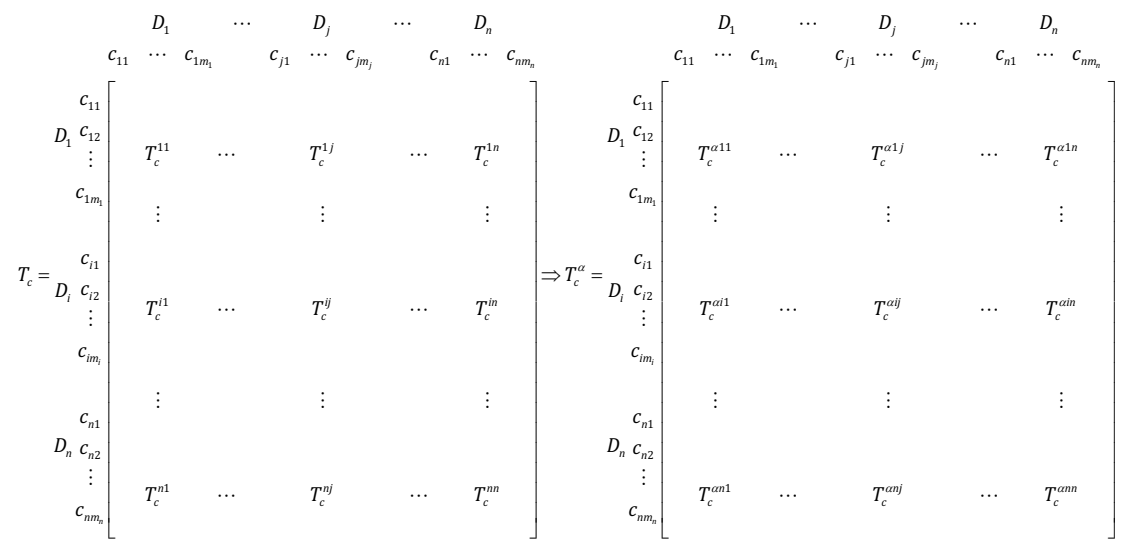

As a sample, the normalization $T_{C}^{\alpha 11}$ is given through Eq. (5) by $d_{C i}^{11}=\sum_{j=1}^{m_{1}} t_{i j}^{11}, i=1,2, \ldots, m_{1}$. The remaining ones $\left(T_{c}^{\alpha n n}\right)$ are similar to the above

$$
T_{c^{\alpha 11}}=\left[\begin{array}{ccccc}
t_{c 11}^{11} / d_{c 1}^{11} & \cdots & t_{c 1 j}^{11} / d_{c 1}^{11} & \cdots & t_{c 1 m_{1}}^{11} / d_{c 1}^{11} \\
\vdots & & \vdots & & \vdots \\
t_{c i 1}^{11} / d_{c i}^{11} & \cdots & t_{c i j}^{11} / d_{c i}^{11} & \cdots & t_{c i m_{1}}^{11} / d_{c i}^{11} \\
\vdots & & \vdots & & \vdots \\
t_{c 1 m_{1} 1}^{11} / d_{c m_{1}}^{11} & \cdots & t_{c 1 m_{1} j}^{11} / d_{c m_{1}}^{11} & \cdots & t_{c 1 m_{1} m_{1}}^{11} / d_{c m_{1}}^{11}
\end{array}\right]=\left[\begin{array}{ccccc}
t_{c 11}^{\alpha 11} & \cdots & t_{c 1 j}^{\alpha 11} & \cdots & t_{c 1 m_{1}}^{\alpha 11} \\
\vdots & & \vdots & & \vdots \\
t_{c i 1}^{\alpha 11} & \cdots & t_{c i j}^{\alpha 11} & \cdots & t_{c i m_{1}}^{\alpha 11} \\
\vdots & & \vdots & & \vdots \\
t_{c m_{1} 1}^{\alpha 11} & \cdots & t_{c m_{1} j}^{\alpha 11} & \cdots & t_{c m_{1} m_{1}}^{\alpha 11}
\end{array}\right]
$$

The normalized total-influence matrix $T_{c}^{\alpha}$ by dimensions (clusters) is transposed, and after then, the unweighted supermatrix is obtained as shown in Eq. (6)

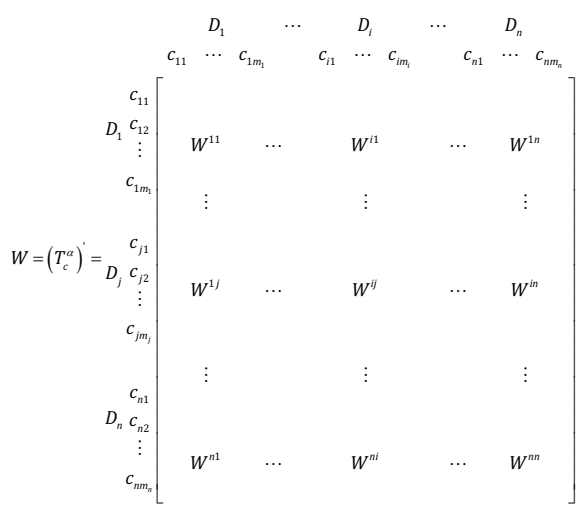

where $D_{n}$ denotes then $n$th cluster, $c_{n m}$ stands for the $m$ th element in the $n$th cluster, and $W^{i j}$ is the principal eigenvector of the influence of each element in the comparison of the $j$ th cluster and the $i$ th cluster. Thus, $\mathrm{W}^{i j}=$ [0] when the $j$ th cluster has no influence. 
Step 8: Obtaining the weighted supermatrix $W^{\alpha}$. It is created by multiplying the normalized matrix, which is constructed from the DEMATEL method. In Eq. (7), each column is summed for the normalization. $t_{D}{ }^{i j}$ is an element of the $T_{D}$ matrix

$T_{D}=\left[\begin{array}{ccccc}t_{D}^{11} & \cdots & t_{D}^{1 j} & \cdots & t_{D}^{1 n} \\ \vdots & & \vdots & & \vdots \\ t_{D}^{i 1} & \cdots & t_{D}^{i j} & \cdots & t_{D}^{i n} \\ \vdots & & \vdots & & \vdots \\ t_{D}^{n 1} & \cdots & t_{D}^{n j} & \cdots & t_{D}^{n n}\end{array}\right]$

The total-influence matrix $T_{D}$ needs to be normalized by diving its elements in row $i$ by $d_{i}=\sum_{j=1}^{n} t_{D}^{i j}, i=1,2, \ldots, n$ as shown in Eq. (8). It is called as $T_{D}^{\alpha}$

$T_{D}^{\alpha}=\left[\begin{array}{ccccc}t_{D}^{11} / d_{1} & \cdots & t_{D}^{1 j} / d_{1} & \cdots & t_{D}^{1 n} / d_{1} \\ \vdots & & \vdots & & \vdots \\ t_{D}^{i 1} / d_{i} & \cdots & t_{D}^{i j} / d_{i} & \cdots & t_{D}^{i n} / d_{i} \\ \vdots & & \vdots & & \vdots \\ t_{D}^{n 1} / d_{n} & \cdots & t_{D}^{n j} / d_{n} & \cdots & t_{D}^{n n} / d_{n}\end{array}\right]=\left[\begin{array}{ccccc}t_{D}^{\alpha 11} & \cdots & t_{D}^{\alpha 1 j} & \cdots & t_{D}^{\alpha 1 n} \\ \vdots & & \vdots & & \vdots \\ t_{D}^{\alpha i 1} & \cdots & t_{D}^{\alpha i j} & \cdots & t_{D}^{\alpha i n} \\ \vdots & & \vdots & & \vdots \\ t_{D}^{\alpha n 1} & \cdots & t_{D}^{\alpha n j} & \cdots & t_{D}^{\alpha n n}\end{array}\right]$

The weighted supermatrix is obtained by multiplying the normalized total-influence matrix $T_{D}^{\alpha}$ by the supermatrix $W$ shown as Eq. (9)

$W^{\alpha}=T_{D}^{\alpha} \cdot W=\left[\begin{array}{ccccc}t_{D}^{\alpha 11} \times W^{11} & \cdots & t_{D}^{\alpha i 1} \times W^{1 j} & \cdots & t_{D}^{\alpha 11} \times W^{1 n} \\ \vdots & & \vdots & & \vdots \\ t_{D}^{\alpha 1 j} \times W^{i 1} & \cdots & t_{D}^{\alpha i j} \times W^{i j} & \cdots & t_{D}^{\alpha n j} \times W^{i n} \\ \vdots & & \vdots & & \vdots \\ t_{D}^{\alpha 1 n} \times W^{n 1} & \cdots & t_{D}^{\alpha i 1} \times W^{n j} & \cdots & t_{D}^{\alpha n n} \times W^{n n}\end{array}\right]$

Step 9: Limit the weighted supermatrix by raising it to a sufficiently large power k. In Eq. (11), it is computed until the supermatrix has converged and formed a long-term stable supermatrix to obtain the global priority vectors (i.e., Dematel ANP (DANP) weights). Weights obtained from the DANP are used in MULTIMOORA method.

$\lim _{k \rightarrow \infty}\left(W^{\alpha}\right)^{k}$

MULTIMOORA method is based on the dominance theory and forms with the addition of multiplicative form to MOORA approach introduced by Brauers \& Zavadskas (2012). This approach includes the comparison of three approaches (Ratio System, Reference Point Approach, and Full Multiplicative Form) in order to reach one final ranking by using the dominance theory proposed by Brauers \& Zavadskas (2011). In an MCDM 
problem, with $X=\left[X_{i j}\right]_{m \times n}$ being a decision matrix, consider that $c_{g}, c_{g+1}, \ldots, c_{n}$ associate the beneficial criteria while $c_{g}, c_{g+1}, \ldots, c_{n}$ associate the cost criteria. $X_{i j}$ indicates the value of $i$ th alternative of $j$ th criterion given in Eq. (12). The computation procedures of the MULTIMOORA method are as follows.

Step 10: Normalization of the decision matrix. The evaluation values $x_{i j}$ are normalized to obtain the dimensionless values $\bar{x}_{i j}$ by Eq. (12)

$$
X=\left[x_{i j}\right]_{m \times n}=\left[\begin{array}{cccc}
x_{11} & x_{12} & \cdots & x_{1 n} \\
x_{21} & x_{22} & \cdots & x_{2 n} \\
\vdots & \vdots & \ddots & \vdots \\
x_{m 1} & x_{m 2} & \cdots & x_{m n}
\end{array}\right] \Rightarrow \bar{x}_{i j}=\frac{x_{i j}}{\sqrt{\sum_{i=1}^{m} x_{i j}^{2}}}, i=1,2, \ldots, m ; j=1,2, \ldots, n
$$

Step 11: Obtaining the weighted normalized decision matrix. The weighted normalization matrix is calculated by multiplying the normalized decision matrix obtained in Eq. (12) by DANP weights computed in Eq. (11). The weight of $j$ th criterion is represented by the symbol $W_{j}$ and the weighted normalization matrix can be calculated using Eq. (13)

$v_{i j}=w_{i j} \times \bar{X}_{i j}, i=1,2, \ldots, m ; j=1,2, \ldots, n$

Step 12: The Ratio System model. The overall utility value $y_{i}$ of the $i$ th calculated the overall criteria through Eq. (14). Afterwards, the alternatives are sorted in descending order. For the beneficial criteria, the weighted normalization values need to be added, while, for the cost criteria, the weighted normalization values should be subtracted

$y_{i}=\sum_{j=1}^{g} v_{i j}-\sum_{j=g+1}^{n} v_{i j}, i=1,2, \ldots, m ; j=1,2, \ldots, n$

Step 13: The Reference Point model. Reference points $\tilde{r}_{i j}^{+}$are performed for each criterion by considering the highest values chosen for maximization criteria and the lowest values chosen for the minimization criteria. The maximum distance $\mathrm{d}_{\mathrm{i}}$ between $\tilde{r}_{i j}^{+}$and $v_{i j}$ is calculated and the alternatives are sorted in increasing order in accordance with the maximum distance values

$\tilde{r}_{i j}^{+}=\left\{\begin{array}{l}\max _{i} v_{i j}, j \leq g \\ \min _{i} v_{i j}, j>g\end{array}, d_{i}=\max _{i}\left[\tilde{r}_{i j}^{+}-v_{i j}\right] i=1,2, \ldots, m ; j=1,2, \ldots, n\right.$

Step 14: The Full Multiplicative Form. The computation of maximization and minimization of a purely multiplicative utility function contains the full multiplicative form of multiple criteria. The overall utility $U_{i}$ of $i$ th alternative is calculated by Eq. (16). Ranking of the alternatives is acquired by sorting $U_{i}$ values in descending order 
$U_{i}=\frac{A_{i}}{B_{i}}, i=1,2, \ldots, m$

where $A_{i}=\prod_{j=1}^{g} x_{i j}^{w_{j}}$ is calculated for $i$ th alternative of each criterion to be maximized, and $B_{i}=\prod_{j=g+1}^{n} x_{i j}^{w_{j}}$ is computed for $i$ th alternative of each criterion to be minimized.

Step 15: The Dominance Theory. The dominance theory incorporates the three different subordinate rankings in order to achieve the final ranking of each alternative.

\section{PART-TIME STUDENT SELECTION PROBLEM}

A real-life study is illustrated in this section to demonstrate the applicability of the novel hybrid approach in solving multiobjective decision-making problems. For this reason, the case study was conducted at the Metallurgical and Materials Engineering Department of the Engineering Faculty at Kütahya Dumlupınar University (DPU), Turkey. DPU Management provides opportunities for university students who want to work part-time and earn their own money. The students who work part-time can assist with administrative affairs in departments of faculties. To do so, each willing student must apply to their department chair during a specific time of the academic year. In most faculties, each department has their own secretarial office with administrative staff. During application periods at the beginning of the academic year, the students deliver their application forms to the secretarial offices of their departments. One or two students are selected from the applicants to work part-time for each academic year.

The aim in this case study is to select a student among five bachelor students to work part-time in the Metallurgical and Materials Engineering Department. The decision-making process is carried out by three decisionmakers (DMs) who have experience and expertise in selecting part-time students.

When selecting a student, the commission needs to consider multiple criteria, including qualification, socioeconomic status, and whether that student has already benefited from part-time work before. Moreover, the decision criteria are often related to each other. Therefore, in selecting the right alternative, the commission needs the right selection method. In this study, DMs are requested to discuss the various evaluating criteria, considerations, and decisions related to selecting the most appropriate alternative. All DMs are academic staff in the Metallurgical and Materials Engineering Department of the Engineering Faculty in DPU. The questionnaire form is designed to evaluate the degree of criteria importance. Three experts (DMs) have determined the objective, three main criteria, and seven subcriteria of the decision-making problem by using a brainstorming method. In Figure 2, the general outline of this problem is shown. Five students (alternatives) have been identified, and Tables 1 and 2 present an explanation of the criteria and potential students, respectively. 


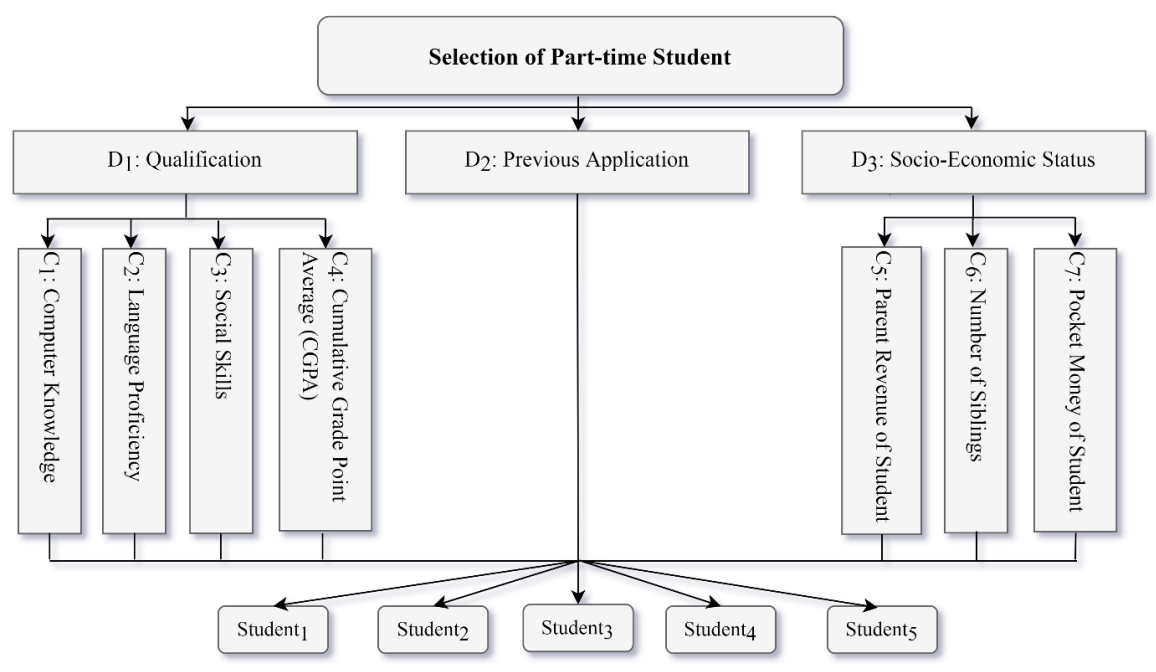

Figure 2. The hierarchical structure of part time student evaluation.

In the decision-making process, the DMs are expected to evaluate pairwise comparisons using the comparison level of DEMATEL. All computations are carried out by Eqs. (1)-(3), and the causal diagram is captured in the horizontal axis $\mathrm{r}+\mathrm{c}$ which is the degree of central role, while the vertical axis $\mathrm{r}-\mathrm{c}$ is the degree of relation as given in Figure 3. In this case, "Socioeconomic status (D3)" is the most influential dimension, while "Cumulative grade point average (C4)" criterion is influenced by the other criteria in Qualification (D1) dimension. "Previous application (D2)" dimension does not have any subcriteria. The dimensions are categorized into two clusters: a cause cluster and effect cluster according to $r$ - c values as shown in Figure 2. The cause cluster contains D1 with positive $\mathrm{r}$ - $\mathrm{c}$ value, whereas the effect cluster comprises D3 with negative $\mathrm{r}$ - c value.

Table 1. Characteristics of potential students.

\begin{tabular}{|l|c|c|c|c|c|}
\hline & CGPA* & Revenue & Number of siblings & Pocket money & Application before? \\
\hline Student 1 & 2.48 & $1850 £ / \mathrm{mth}$ & 2 & $670 £ / \mathrm{mth}$ & No \\
\hline Student 2 & 2.86 & $1700 £ / \mathrm{mth}$ & - & $300 £ / \mathrm{mth}$ & Yes \\
\hline Student 3 & 1.99 & $4100 £ / \mathrm{mth}$ & 1 & $470 £ / \mathrm{mth}$ & No \\
\hline Student 4 & 2.23 & $3000 £ / \mathrm{mth}$ & 1 & $600 £ / \mathrm{mth}$ & No \\
\hline Student 5 & 2.18 & $1800 £ /$ mth & & $470 £ / \mathrm{mth}$ & No \\
\hline
\end{tabular}


Table 2. Explanation of criteria.

\begin{tabular}{|c|c|c|}
\hline Criteria & Definition & $\begin{array}{c}\text { Criteria } \\
\text { Type }\end{array}$ \\
\hline $\mathrm{D}_{1}$ & & \\
\hline $\mathrm{C}_{1}$ & Good computer knowledge is an advantage for a student. & Benefit \\
\hline $\mathrm{C}_{2}$ & $\begin{array}{l}\text { Language proficiency plays critical role for admissions to be able to } \\
\text { fulfill the role. }\end{array}$ & Benefit \\
\hline $\mathrm{C}_{3}$ & Problem-solving skills and cooperating \& helping others. & Benefit \\
\hline $\mathrm{C}_{4}$ & The higher CGPA a student has, the more successful that student is. & Benefit \\
\hline $\mathrm{D}_{2}$ & Each student who has not made any previous applications has a priority. & Cost \\
\hline $\mathrm{D}_{3}$ & The income, education, and occupation of each family member. & \\
\hline $\mathrm{C}_{5}$ & The monthly income of the family of each student. & Cost \\
\hline $\mathrm{C}_{6}$ & Number of school-age siblings. & Benefit \\
\hline $\mathrm{C}_{7}$ & Finance provided by parents or scholarship. & Cost \\
\hline
\end{tabular}

Similarly, the criteria are examined with the same way, and the effect and cause clusters are determined for the criteria in Figure 3. The network relationships and influences among performance aspects constructed from DEMATEL are utilized for ANP calculation. Using Eqs. (4)-(11), the weights of each criterion and the second dimension are obtained for MULTIMOORA. Table 3 indicates that the global weights were obtained by DANP approach. It is shown in Table 3 that the previous application (D2) with a weight of 0.631 is the most important dimension among the three criteria, followed by the socioeconomic status (D3), and qualification (D1) in the process of part-time student evaluation. Each value of the candidates belonging to each criterion/dimension is normalized through Eq. (12) to reach the dimensionless value. Data of each candidate are given in Table 2. Then, the values belonging to each approach are computed using Eqs. (13)-(16). Based on three approaches, the final ranking is obtained by using the dominance rule. Thus, the result of MULTIMOORA is given. According to the DANP and MULTIMOORA approach, the best suitable student who best needs part-time work is the third student as shown in Table 4. 


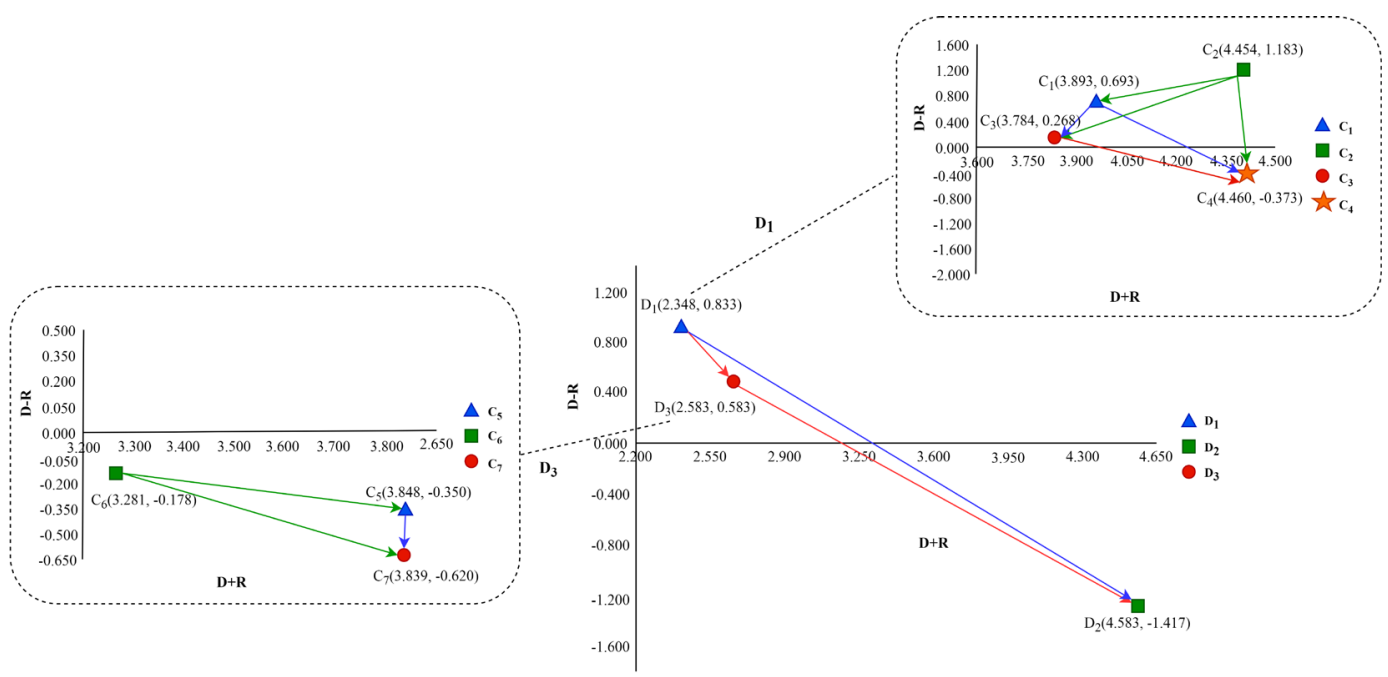

Figure 3. The network relation maps of the dimensions and criteria.

Table 3. The global and local weights for part-time student evaluation performance.

\begin{tabular}{|c|c|l|c|c|c|}
\hline \multirow{2}{*}{ Dimensions } & $\begin{array}{c}\text { Local weights of } \\
\text { dimensions }\end{array}$ & Criteria & $\begin{array}{c}\text { Local } \\
\text { weights of } \\
\text { criteria }\end{array}$ & $\begin{array}{c}\text { Global } \\
\text { weights of } \\
\text { criteria }\end{array}$ & Rank \\
\hline \multirow{2}{*}{$\mathrm{D}_{1}$} & \multirow{2}{*}{0.159} & $\mathrm{C}_{1}$ & 0.214 & 0.034 & 8 \\
\cline { 3 - 6 } & & $\mathrm{C}_{2}$ & 0.233 & 0.037 & 6 \\
\cline { 3 - 6 } & & $\mathrm{C}_{3}$ & 0.220 & 0.035 & 7 \\
\cline { 3 - 6 } & \multirow{2}{*}{0.631} & $\mathrm{C}_{4}$ & 0.332 & 0.053 & 5 \\
\hline \multirow{2}{*}{$\mathrm{D}_{2}$} & \multirow{2}{*}{0.210} & $\mathrm{C}_{5}$ & 1 & 0.631 & 1 \\
\cline { 3 - 6 } & & $\mathrm{C}_{6}$ & 0.353 & 0.074 & 3 \\
\cline { 3 - 6 } & $\mathrm{D}_{3}$ & $\mathrm{C}_{7}$ & 0.369 & 0.078 & 2 \\
\hline
\end{tabular}

Table 4. The final ranking of students according to the dominance rule.

\begin{tabular}{|c|c|c|c|c|}
\hline The ration system & $\begin{array}{c}\text { The reference point } \\
\text { approach }\end{array}$ & $\begin{array}{c}\text { The full multiplicative } \\
\text { form }\end{array}$ & MULTIMOORA & Rank \\
\hline $\mathrm{S}_{4}$ & $\mathrm{~S}_{3}$ & $\mathrm{~S}_{2}$ & $\mathrm{~S}_{3}$ & 1 \\
\hline $\mathrm{S}_{5}$ & $\mathrm{~S}_{5}$ & $\mathrm{~S}_{5}$ & $\mathrm{~S}_{5}$ & 2 \\
\hline $\mathrm{S}_{1}$ & $\mathrm{~S}_{4}$ & $\mathrm{~S}_{4}$ & $\mathrm{~S}_{4}$ & 3 \\
\hline $\mathrm{S}_{2}$ & $\mathrm{~S}_{1}$ & $\mathrm{~S}_{3}$ & $\mathrm{~S}_{1}$ & 4 \\
\hline $\mathrm{S}_{3}$ & $\mathrm{~S}_{2}$ & $\mathrm{~S}_{1}$ & $\mathrm{~S}_{2}$ & 5 \\
\hline
\end{tabular}




\section{SENSITIVITY ANALYSIS}

In this study, the sensitivity analysis was performed by considering the decision makers' different weights and criteria weights. In our case, we assumed the weights of three DMs are equal. However, the final ranking can change when the different weights of DMs are considered. Thus, we defined three scenarios for the weights of DMs. The weights are standardized in order to ensure that the sum of weights is always 1 . In the first scenario, the weights are considered as $0.8,0.1$, and 0.1 , and the final ranking is computed as $S_{3} \succ S_{5} \succ S_{4} \succ S_{1} \succ S_{2}$. In the second scenario, the weights are considered as 0.1, 0.8, and 0.1, and the final ranking is computed as $S_{2} \succ S_{5} \succ S_{4} \succ S_{1} \succ S_{3}$. In the last scenario, the weights are considered as $0.1,0.1$, and 0.8 , and the final ranking is computed as $S_{3} \succ S_{5} \succ S_{4} \succ S_{2} \succ S_{1}$. Accordingly, it is observed that the final ranking of the students changes when the weight of the second decision maker is larger than the other ones.

At the second stage, the sensitivity analysis was carried out, taking into account the different weights for the dimensions. Thus, the four scenarios are planned in which all dimension weights are equal $(0.33,0.33,0.33)$, the weight of the first dimension is greater than the weights of the remaining dimensions $(0.8,0.1,0.1)$, the weight of the second dimension is greater than the weights of the remaining dimensions $(0.1,0.8,0.1)$, and the weight of the third dimension is greater than the weights of the remaining dimensions $(0.1,0.1,0.8)$. As seen in Figure 4 , the different rankings of the alternatives are computed by considering the different dimension weights. The radar chart has five layers, and each layer defines the ranking, meaning that the innermost layer is the lowest ranking, and the outermost layer is the highest ranking. Based on the radar chart of the four scenarios, the rankings change in terms of the different scenarios, as shown in Figure 4. According to these scenarios, it is observed that the most preferred alternative is $\mathrm{S}_{4}$.

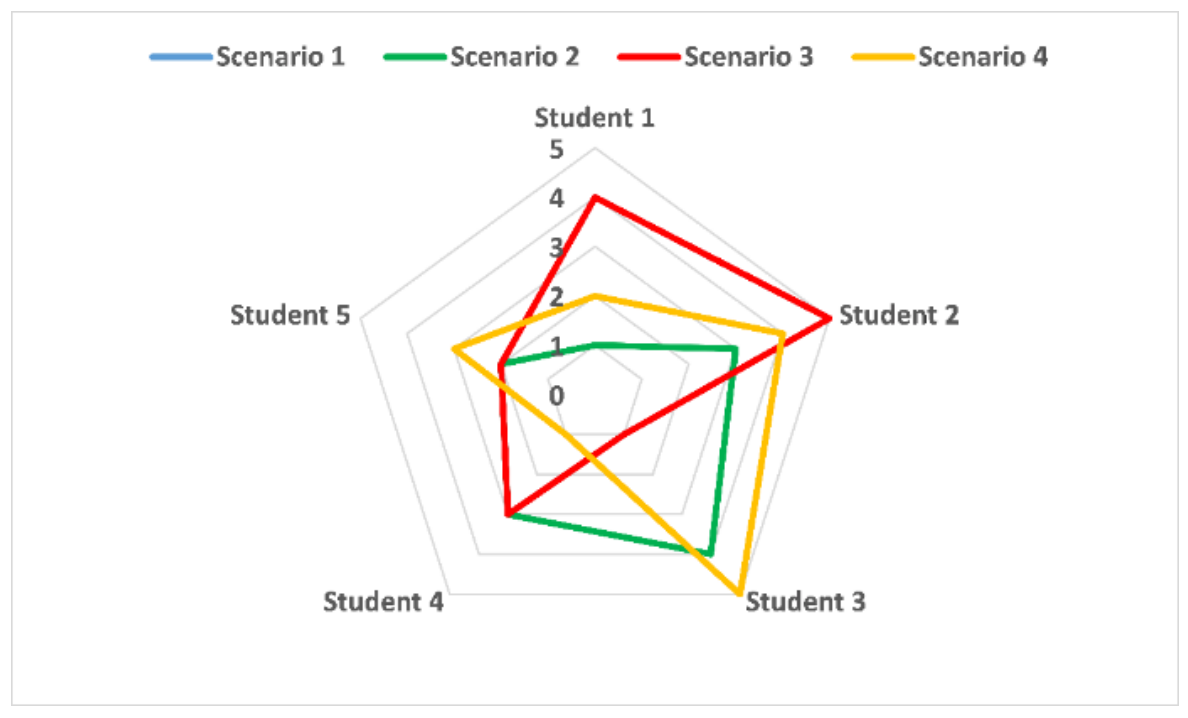

Figure 4. Radar chart for the ranking in different scenarios.

\section{DISCUSSION OF RESULTS AND CONCLUSION}

In this paper, the DEMATEL-modified ANP and MULTIMOORA approach are proposed to rank the students who most need to work part-time. The weight of each criterion is determined with the DEMATEL-modified ANP approach. The students are then ranked by the MULTIMOORA approach using the weight values obtained from 
the DEMATEL-modified ANP approach. The applicability of the model is illustrated by a real-life case study. Because of this, students are evaluated in a fair environment. The results indicate that the S3 student is the most suitable student among the feasible alternative to work part-time at the Metallurgical and Materials Engineering Department in DPU, closely followed by the S5 student and the S4 student. Afterward, the sensitivity analysis was performed by considering the changing of the decision makers' weights and the criteria weights. After applying the sensitivity of the dimension weights, the S4 student is mostly preferred as shown in Figure 4.

This study contributes to the literature by considering the integrated DEMATEL and modified ANP and MULTIMOORA in the field of part-time student selection evaluation. The ANP method presents a more accurate analysis by tackling interdependent relationships. Since the ANP method takes more time with the increased number of pair-wise comparison matrices, DEMATEL is used for dealing with the inner dependencies of criteria to overcome this shortcoming. Thus, DANP is used for the determination of criteria weights. Then, MULTIMOORA is utilized to rank the alternatives ( 5 students) by using the dominance rule.

The data collection process is the main limitation of this study. Documents received from students can be used for data collection and analysis. In order to avoid the subjective consciousness, the number of respondents may be increased in the future research for gathering data from respondents. Regarding future work, the proposed hybrid approach should be developed in a "fuzzy environment," using linguistic terms. This approach ensures that the decision-makers are able to describe and compute the uncertainty in a more flexible environment. Interval type- 2 fuzzy MCDM, interval type-2 hesitant fuzzy set method, and intuitionistic fuzzy set studied in recent years can be used for the same problem, and the results can be compared in further studies. Further, these studies can be expanded upon with more criteria. Moreover, the performance of the proposed approach can be compared to the newly presented MCDM methods, such as FUCOM and LBWA, and the variants formed by integrating these methods with other ranking methods (TOPSIS, ARAS, EDAS, CODAS, MAIRCA, COPRAS, etc.).

\section{REFERENCES}

Alossta, A., Elmansouri, O., \& Badi, I. 2021.Resolving a location selection problem by means of an integrated ahp-rafsi approach. Reports in Mechanical Engineering 2(1): 135-142.

Baki, N. A., Norddin, N. I., \& Azaman, W. A. W. 2017. Application of analytic hierarchy process for selecting rivebest student. Journal of Applied Environmental and Biological Sciences 7(1): 69-73.

Bongo, M. F., Alimpangog, K. M. S., Loar, J. F., Montefalcon, J. A., \& Ocampo, L. A. 2018.An application of dematel-anp and promethee ii approach for air trafficcontrollers' workload stress problem: A case of mactan civil aviation authority of the philippines. Journal of Air Transport Management 68: 198-213.

Brauers, W. K. M., \& Zavadskas, E. K. 2011.Multimoora optimization used to decide on a bank loan to buy property. Technological and economic developmentof economy17 (1): 174-188.

Brauers, W. K. M., \& Zavadskas, E. K. 2012.Robustness of multimoora: a methodfor multi-objective optimization. Informatica 23(1): 1-25.

Büyüközkan, G., \& Güleryüz, S. 2016.An integrated dematel-anp approach for renewable energy resources selection in turkey. International Journal of Production Economics 182: 435-448.

Chen, I.S. 2016. A combined mcdm model based on dematel and anp for theselection of airline service quality improvement criteria: A study based onthe taiwanese airline industry. Journal of Air Transport Management 57, 7-18. 
De Farias Aires, R. F., Ferreira, L., De Araujo, A. G., \& Borenstein, D. 2017. Student selection in a Brazilian university: Using a multi-criteria method. Journal of the Operational Research Society 69(4): $528-540$.

Deliktas, D., \& Ustun, O. 2017. Student selection and assignment methodology based on fuzzy MULTIMOORA and multichoice goal programming. International Transactions in Operational Research 24(5): 1173-1195.

Dinçer, H., Yüksel, S., \& Martínez, L. 2019.Interval type 2-based hybrid fuzzyevaluation of financial services in e7 economies with dematel-anp and mooramethods. Applied Soft Computing Journal 79: 186-202.

Fadlina, F., Sianturi, L. T., Karim, A., Mesran, \& Siahaan, A. P. U. 2017. Best Student Selection Using Extended Promethee II Method. International Journal of Recent Trends in Engineering and Research 3(8): $21-29$.

Gabus, A., \& Fontela, E. 1973. Perceptions of the World Problem Atique: Communication Procedure, Communicating with Those Bearing Collective Responsibility. DEMATEL Report No.1. In: Battelle Geneva Research Centre (C. 01). Geneva.

Hasan, P., Utami, E., Yunita, S., Pawan, E., \& Kaharuddin. 2019. Selection of scholarship acceptance using AHP and TOPSIS methods. 2019 International Conference on Information and Communications Technology (ICOIACT 2019), 920-925. Kuala Lumpur, Malaysia.

Kargari, M. 2018.Ranking of performance assessment measures at tehran hotelby combining dematel, anp, and servqual models under fuzzy condition. Mathematical Problems in Engineering.

Koca, G.,\&Yıldırım, S. 2021. Bibliometric analysis of dematel method. Decision Making: Applications in Management and Engineering 4(1): 85-103.

Mostafaeipour, A.,Alvandimanesh, M., Najafi, F. \&Issakhov, A. 2021. Identifying challenges and barriers for development of solar energy by using fuzzy best-worst method: A case study. Energy 226: 120355.

Pamučar, D.,Stevic, Z., \&Sremac, S. 2018. A new model for determining weight coefficients ofcriteria in mcdm models: full consistencymethod (fucom). Symmetry 10(9): 393.

Pamučar, D.,Ecer, F., Cirovic, G., \&Arlasheedi, M.A. 2020. Application of improved best worst method (bwm)in real-world problems. Mathematics 8(8): 1342.

Petrović, I.B.,\& Kankaraš, M. 2018. Dematel-Ahp Multi-Criteria Decision Making Model for the Determination and Evaluation of Criteria for Selecting an Air Traffic Protection Aircraft. Decision Making: Applications in Management and Engineering 1(2): 93-110.

Poudeh, H. D., Cheshmberah, M., Torabi, H., Karimi Gavareshki, M. H., \& Hosnavi, R. 2019.Determining and prioritizing the factors influencing the outsourcing ofcomplex product systems $\mathrm{r} \& d$ projects employing anp and grey-dematelmethod (case study: Aviation industries organization, iran). Technology in Society 56: $57-68$.

Rezaei, J. 2015. Best-worst multi-criteria decision-making method. Omega 53: 49-57.

Saaty, T. L. 1996. Decision Making with Dependence and Feedback: The Analytic Network Process. RWS Publications,ISBN 0-9620317-9-8, Pp. 370.

Shao, Q. G., Liou, J. J. H., Weng, S. S., \& Chuang, Y. C. 2018.Improving the green building evaluation system in china based on the danp method. Sustainability 10(4): 1-20. 
Siahaan, A.P.U., \&Mesran, M. 2017. Best student selection using extended promethee ii method. International Journal of Recent Trends in Engineering \&Research 3(8): 21-29.

Vierula, J., Haavisto, E., Hupli, M., \& Talman, K. 2020. The assessment of learning skills in nursing student selection: A scoping review. Assessment and Evaluation in Higher Education 45(4): 496-512.

Žižović, M.,\&Pamučar, D. 2019. New model for determining criteria weights: Level Based Weight Assessment (LBWA) model. Decision Making: Applications in Management and Engineering 2(2): 126-137. 


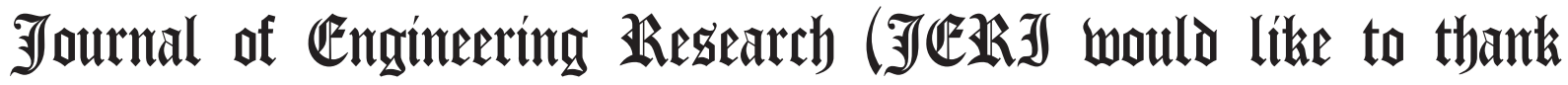
the distinguished indibiduals who put an appreciated effort in refereeing the papers publisted in this issue. Bour valuable time and imput is biathly recoumised by the editorial board of $\mathfrak{J} \mathbb{E}$ R, we look forward to more cooperation in the future to kerp $\mathfrak{J}$ e 